\title{
Dual-Frequency Miniaturized Substrate Integrated Waveguide Quarter-Mode Cavity-Backed Antenna Based on Minkowski Fractal Gap with Orthogonal Polarization Radiation Characteristics
}

\author{
Zihao Fu, Tianliang Zhang $\mathbb{D}$, You Lan, Tianhai Wu, Wenxing Huang, and Leilei He \\ School of Aeronautics and Astronautics, University of Electronic Science and Technology of China, Chengdu, China \\ Correspondence should be addressed to Tianliang Zhang; ztl@uestc.edu.cn
}

Received 20 January 2019; Accepted 25 March 2019; Published 15 April 2019

Academic Editor: Chien-Jen Wang

Copyright (C) 2019 Zihao Fu et al. This is an open access article distributed under the Creative Commons Attribution License, which permits unrestricted use, distribution, and reproduction in any medium, provided the original work is properly cited.

\begin{abstract}
A novel quarter-mode substrate integrated waveguide miniaturized cavity-backed antenna loading Minkowski fractal gap is presented in this paper. Firstly, the resonant frequency of the rectangular substrate integrated waveguide resonator is reduced by etching the fractal gap in the resonator to achieve miniaturization. In addition, because of the symmetry of electric field distribution in second and third order resonant modes, the cavity can be segmented into a quarter-mode and the other order resonance modes with asymmetric electric field distribution can be suppressed according to the cavity model theory. Hence, the cavity size is further reduced. The dimension of designed antenna is $0.26 \lambda_{0} \times 0.26 \lambda_{0}\left(\lambda_{0}\right.$ is the wavelength in free space; in this paper, the corresponding wavelength is $3.6 \mathrm{GHz}$ ). Moreover, the orthogonal polarization of the proposed antenna in two frequency bands is achieved because the electric field is orthogonal in second and third order resonant modes. This dual-frequency orthogonal polarization characteristic enables antenna to communicate in two working bands and has good channel isolation. The simulated and measured results are consistent. The antenna gain is $4.67 \mathrm{dBi}$ and $3.4 \mathrm{dBi}$, respectively, at $3.7 \mathrm{GHz}$ and $4.6 \mathrm{GHz}$.
\end{abstract}

\section{Introduction}

With the development of wireless communication technology, the miniaturization of antennas has been the pursuit of antenna engineers. Fractal technology is always an important method to solve this problem of path antenna miniaturization. The effective current path on the resonant patch can be effectively increased by the fracturing of the resonant patch, in which the antenna miniaturization can be realized [1]. In recent years, there have been many reports on the miniaturization and high order mode suppression of patch antenna by fractal technology [2-4].

The cavity-backed antenna is a kind of slot antenna which can realize radiation by opening a gap in resonant cavity. Compared to ordinary microstrip antennas, cavity-backed antennas have larger front-to-back ratio [5] and radiation gain [6]. In recent years, the substrate integrated waveguide (SIW) circuit is always the focus of researchers. Through the inductive metallization hole and copper surface at top and bottom, the waveguide is integrated in substrate [7]. It is also an effective way to realize cavity miniaturization [8]. A quarter-mode substrate integrated waveguide (QMSIW) resonator is presented in [9]. The cavity operating at the original frequency point in a quarter-mode of the electromagnetic field distribution of the original cavity is to realize the miniaturization of cavity antenna. The paper in [10] reports a novel QMSIW cavity-backed antenna. The size of the antenna is further reduced and the high order mode is inhibited by using the Sierpinski fractal geometry gap.

Dual-frequency antenna has two operating frequencies. It can satisfy the system's requirement for two working frequencies by a single antenna. Hence it reduces the size of antenna module in wireless system and reduces the design cost. When the dual-frequency antenna has orthogonal radiation polarization characteristics in two working bands, this antenna will improve the channel isolation for wireless systems. In [11, 12], 


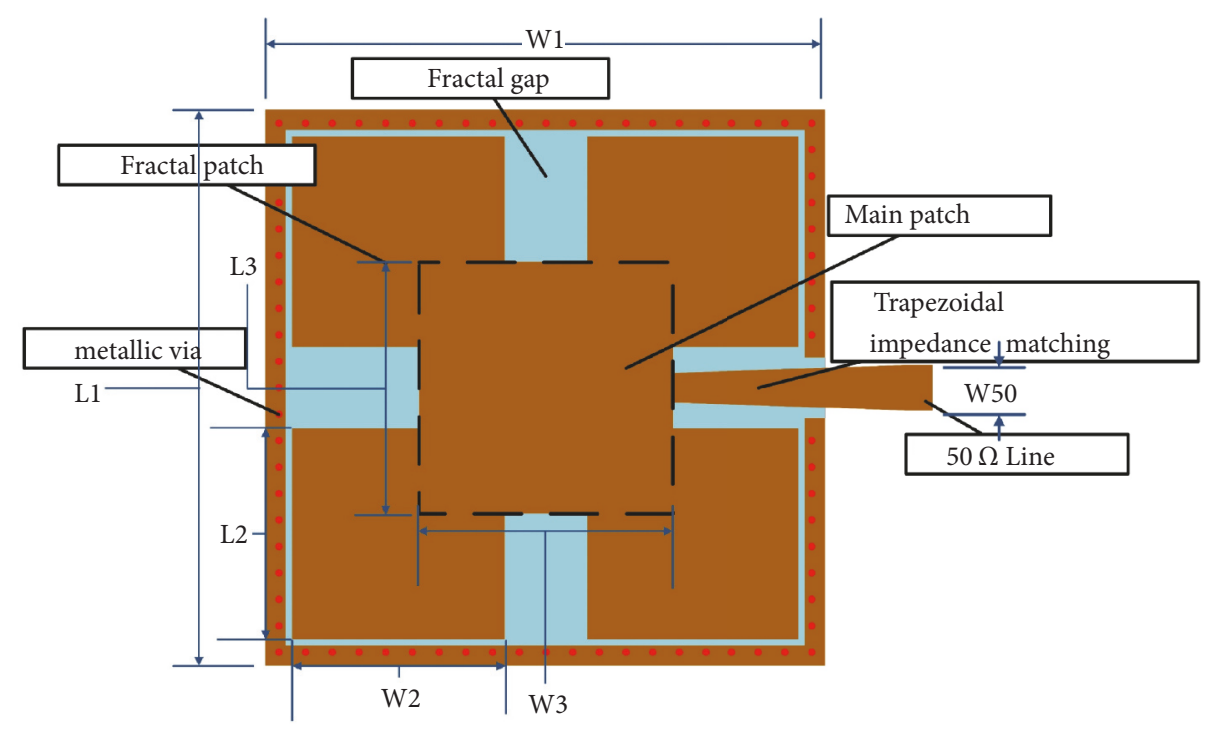

FIgURE 1: Whole mode cavity structure diagram.

a dual-frequency dual-sense circularly polarized antenna is presented. This antenna has dual frequency characteristics. Moreover, they have orthogonal polarization characteristics in different frequency bands.

In this paper, a dual-frequency miniaturized QMSIW cavity-backed antenna with orthogonal linear polarization radiation characteristics is presented. A fractal gap etched in the upper surface of the SIW resonant cavity. On the one hand, the electrical size of the cavity is reduced due to the increase of the radiation aperture of the resonator. On the other hand, the fractal gap makes the cavity have unique electric field distribution. The symmetrical electric field distribution of second and third order resonant modes is not suppressed after a quarter of the cut. In addition, the high order modes are suppressed. Because the electric field distribution of second and third orders is orthogonal after segmentation, the dual orthogonal linear polarization is realized in the proposed antenna. Simulation analysis and experimental results show that, after the fractal and quartermode treatment, the radiation characteristics of the antenna remain good.

\section{Antenna Design}

2.1. Minkowski Fractal Gap Design. As shown in Figure 1, the first order Minkowski fractal gap is etched in the rectangular substrate integrated waveguide resonator, where the blue region is the fractal gap. As shown in Figure 2, compared with rectangular gap, fractal gap can cut the current lines, increasing the effective radiation aperture of cavity-backed antenna, and then the resonance point moves to low frequency to achieve miniaturization. Due to the influence of fractal slots, the resonant mode of proposed cavity is no longer equivalent to a rectangular resonator. Therefore, there are no traditional $\mathrm{TE}_{\mathrm{mn} 0}$ modes in proposed SIW cavity, and unique fractal mode is formed. The full-wave simulation software HFSS shows the resonance frequency of second mode (mode A) is close to third mode (mode B) as shown in Figure 2, and the other order modes existed. Figure 3 shows the electric field distribution of mode $\mathrm{A}$ and mode $\mathrm{B}$.

2.2. QMSIW Design. The process of mode segmentation of the quarter-mode is shown in Figures 4(a) and 4(b). With the distribution of electric field changing from fullmode to quarter-mode, the size of the antenna has been further reduced. Moreover, the first order and high order modes with asymmetric electric distributions are effectively suppressed. As shown in Figure 5, except for mode A and mode $B$, there is no other resonant mode with reflection coefficient less than $-10 \mathrm{~dB}$ after segmentation. The resonant frequencies of mode $A$ and mode $B$ remain unchanged before and after segmentation. Figure 6 shows the mode $A$ and mode B electric field distribution of QMSIW processing, and the electric field is well preserved after segmentation. The quarters of modes $\mathrm{A}$ and $\mathrm{B}\left(\mathrm{A}^{\mathrm{QM}}, \mathrm{B}^{\mathrm{QM}}\right)$ are well preserved. In addition, the electric field distributions of mode $A^{\mathrm{QM}}$ and mode $\mathrm{B}^{\mathrm{QM}}$ are orthogonal $\left( \pm 45^{\circ}\right)$ as Figure 6 has shown.

2.3. High-Order Mode Suppression. From Figure 5, the first, fourth, and fifth order modes of proposed resonator are suppressed after quarter mode treatment. Figure 7 shows the electric field distribution in the first, fourth, and fifth order modes of full-mode resonator. The red arrow in Figure 7 is the direction of the electric field changing with the feed phase increased.

For convenience of analysis, the full-mode resonator is divided into five parts, as shown in Figure 7(b). There is an equivalent electric wall in the central transverse axis of part 1 as Figure 7 has shown. When part 1 is cut from the central axis and only the lower left part is retained, the customary mode of part 1 will not be excited due to the absence of the 


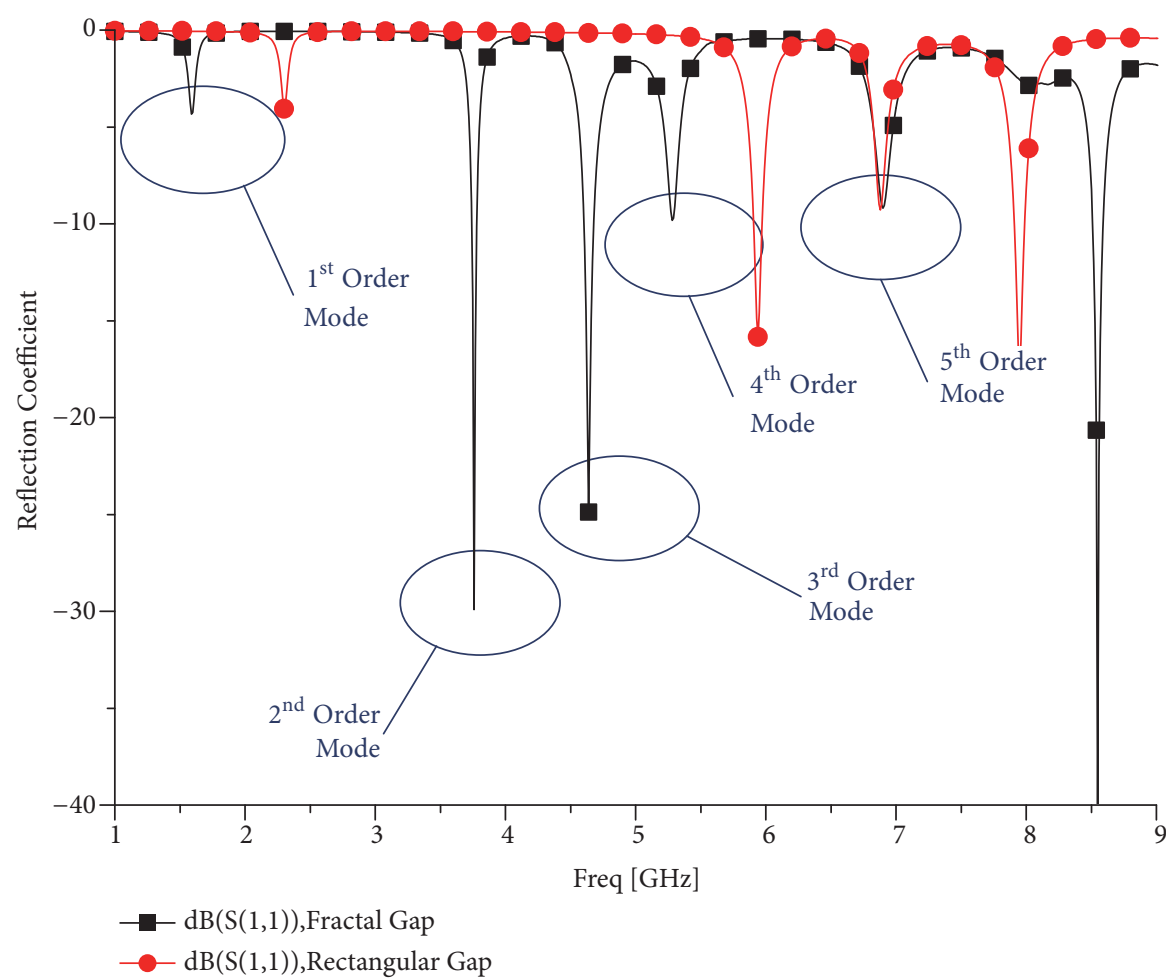

FIGURE 2: Whole mode resonator return loss characteristic.

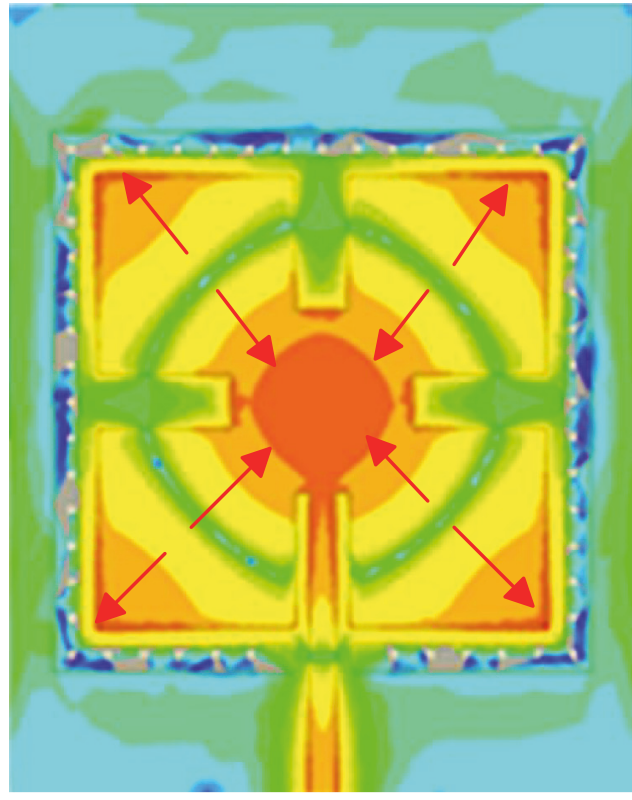

(a)

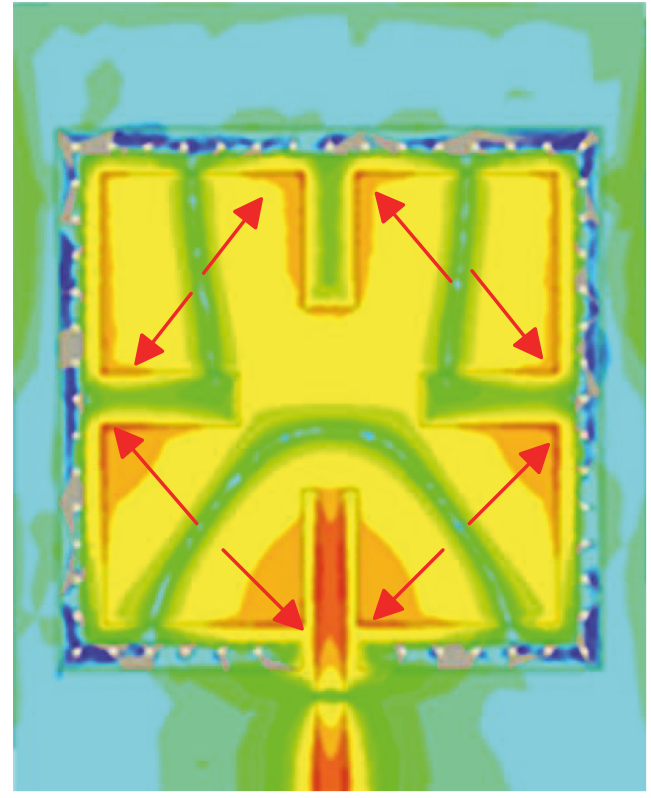

(b)

FIGURE 3: Electric field distribution of full-mode: (a) mode A; (b) mode B.

upper part. Hence the first, fourth, and fifth order modes are suppressed after segmentation.

Unlike other modes, part 1 of mode A can be equivalent to quasi- $\mathrm{TE}_{101}$ mode. The other parts are centrosymmetrically distributed. Therefore, the central axis of mode A can be equivalent to the ideal magnetic wall, which is not affected by the segmentation. The mode $\mathrm{B}$ electric field can also be equivalent to the centrosymmetric distribution, and the electric field intensity of part 1 is weak. Hence the excitation of mode B will not be affected after segmentation. 


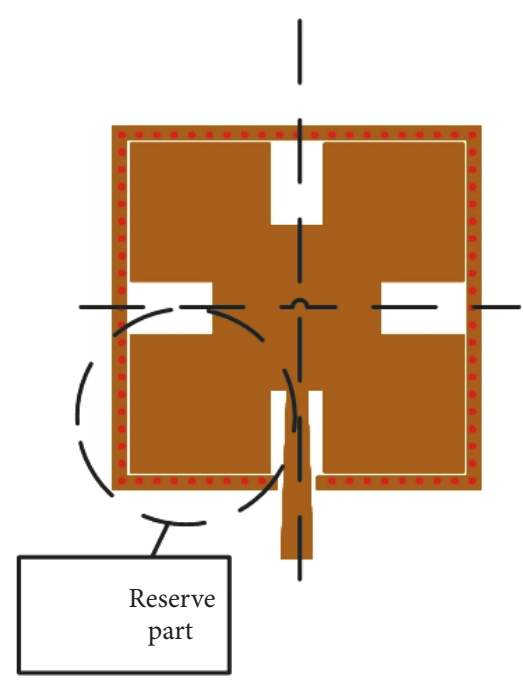

(a)

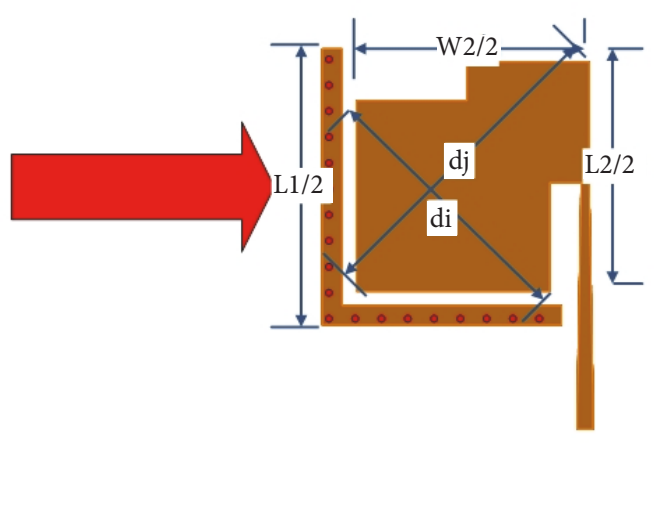

(b)

FIGURE 4: Process of the evolution of the proposed quarter-mode: (a) layout of full-mode; (b) layout of quarter-mode.

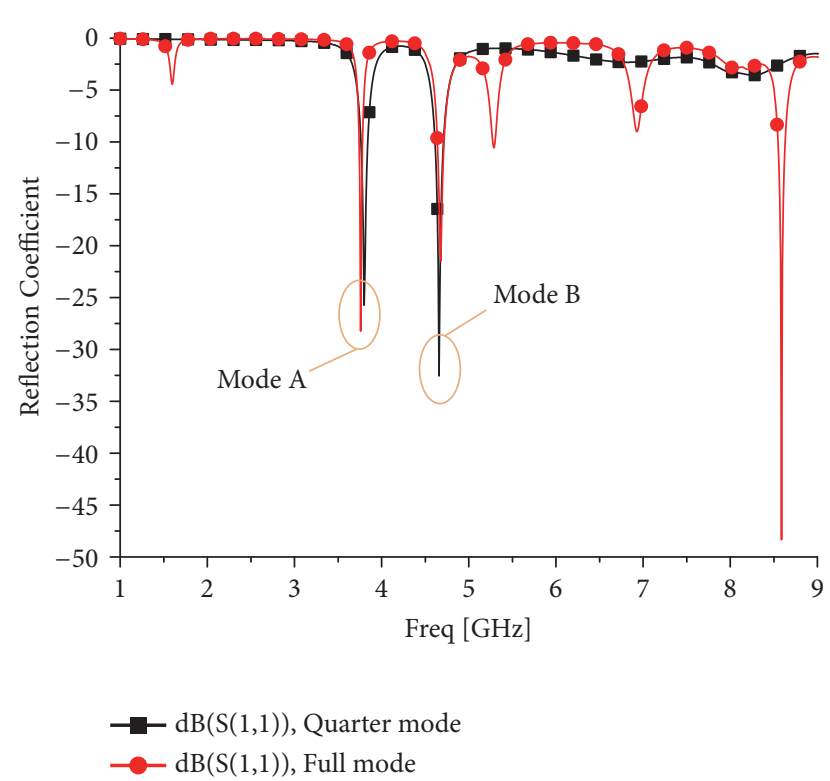

FIGURE 5: Comparison of reflection coefficient between full-mode and quarter-mode.

2.4. Parameter Study. As shown in Figure 8(a), the distance dj between the main patch centre and fractal patch center in Figure 4(b) affects the resonant length of mode A. With the increase of dj length, the resonant length of mode $A^{Q M}$ increased, and the resonance frequency of mode $\mathrm{A}\left(f_{\text {mode } A}^{\mathrm{QM}}\right)$ moved to low frequency. Conversely, when reducing the length of $\mathrm{dj}, f_{\text {mode A }}^{\mathrm{Q} M}$ moved to high frequency as shown in Figure $8(\mathrm{a})$. In addition, the resonance frequency of mode $\mathrm{B}^{\mathrm{QM}}\left(f_{\text {mode B }}^{\mathrm{QM}}\right)$ is almost unaffected by tuning length of $\mathrm{dj}$.

Similarly, increasing the diagonal length di of the fractal patch in Figure 4(b) can increase the resonance length of mode $\mathrm{B}$ and make $f_{\text {mode } B}^{\mathrm{QM}}$ move to low frequency. Decreasing the length of di can make $f_{\text {mode B }}^{\mathrm{QM}}$ move to high frequency, as shown in Figure 8(b).

According to the above principle, the resonant frequency of antenna can be determined by adjusting the length of di and $\mathrm{dj}$ according to user's needs. The resonant frequencies $f_{\text {mode } A}^{\mathrm{QM}}$ and $f_{\text {mode B }}^{\mathrm{QM}}$ are finally determined to be $3.7 \mathrm{GHz}$ and $4.6 \mathrm{GHz}$ to support wireless communication systems in different frequency bands. The proposed antenna circuit is etched on the Rogers 4350 substrate $(\varepsilon=3.48, \tan \delta=0.0012)$.

The thickness of the substrate affects the quality factor $\mathrm{Q}$ of proposed cavity and then affects the performance of the antenna. Table 1 shows the effect of substrate thickness on antenna radiation characteristics and bandwidth. With the increase of the thickness of the substrate, the radiation characteristics of the antenna become better. Because the resonant electric field of the antenna in two frequency bands is orthogonal, the radiation polarization of the antenna in two working bands is also orthogonal.

The size of the ground also affects the antenna radiation and frequency response. Figure 9 shows the effect of different size of ground on antenna $S$ parameters. The effect of ground size on antenna radiation performance is shown in Table 2. Because the antenna retains part of the SIW wall, the size outside the wall does not need to be considered. Moreover, in order to ensure impedance matching, the ground of the feeding microstrip line also needs to be preserved.

From Figure 9, the resonant frequencies of antenna mode $\mathrm{A}^{\mathrm{QM}}$ and mode $\mathrm{B}^{\mathrm{QM}}$ do not change with the size of the antenna ground increase. From Table 2, the gain of the antenna increased with the size of the ground increasing, but the change is small.

The antenna parameters are finally determined as $\mathrm{Ll}=$ $40 \mathrm{~mm}, \mathrm{~W} 1=40 \mathrm{~mm}, \mathrm{~L} 2=19 \mathrm{~mm}, \mathrm{~W} 2=19 \mathrm{~mm}, \mathrm{~L} 3=16.5 \mathrm{~mm}$, $\mathrm{W} 3=16.5 \mathrm{~mm}, \mathrm{~d} 1=0.4 \mathrm{~mm}, \mathrm{~W} 50=3.4 \mathrm{~mm}, \mathrm{dj}=17 \mathrm{~mm}$, and $\mathrm{di}=$ $23.3 \mathrm{~mm}$. The substrate thickness of the proposed antenna is $1.524 \mathrm{~mm}$. The proposed antenna is fed by grounded coplanar waveguide (GCPW) which can effectively reduce the $50 \mathrm{ohm}$ 


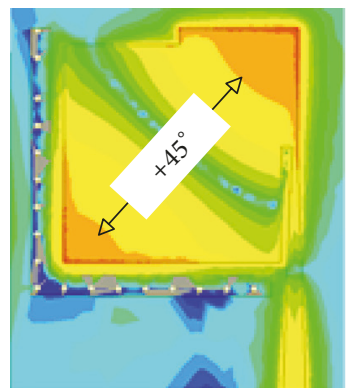

(a)

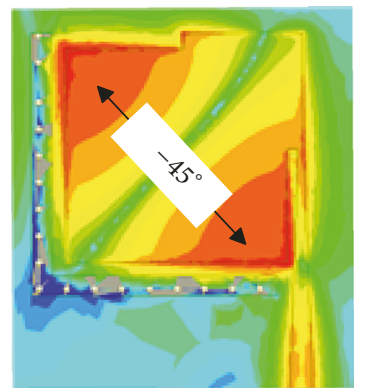

(b)

Figure 6: Electric field distribution of quarter-mode: (a) mode $\mathrm{A}^{\mathrm{QM}}$; (b) mode $\mathrm{B}^{\mathrm{QM}}$.

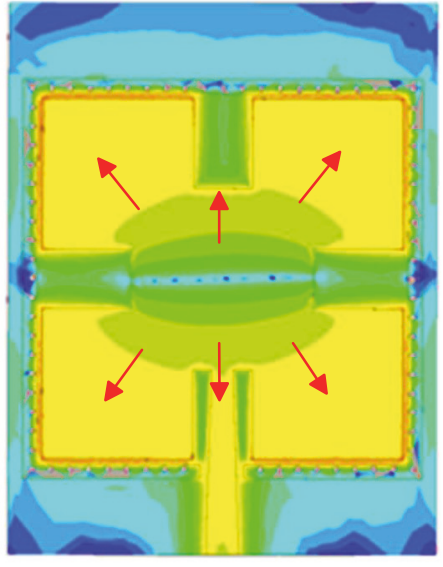

(a)

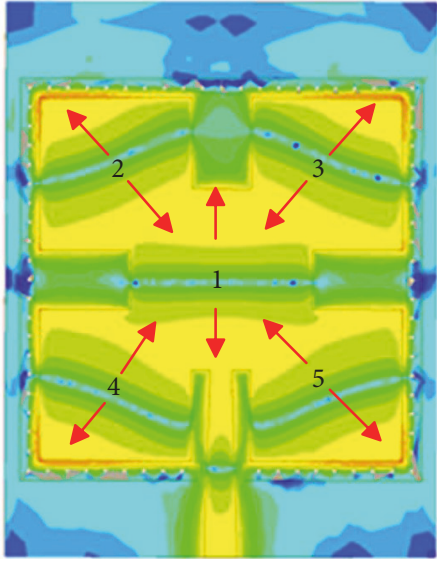

(b)

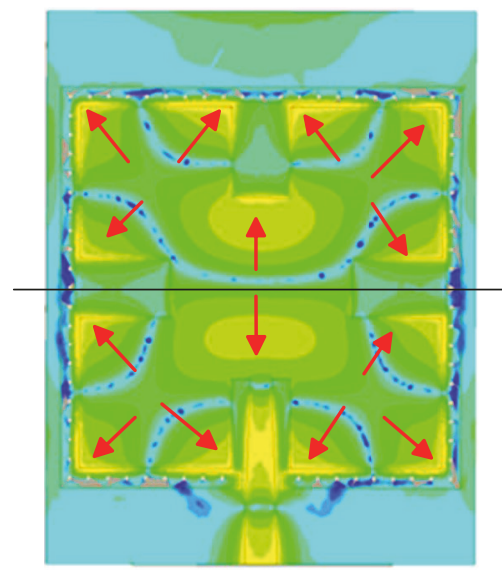

(c)

FIgURE 7: Electric field distribution of other modes: (a) first mode; (b) fourth mode; (c) fifth mode.

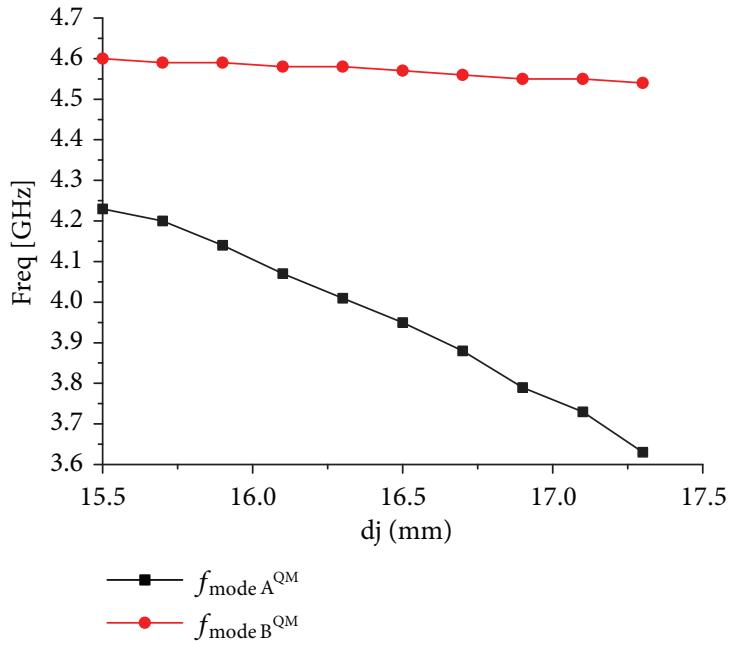

(a)

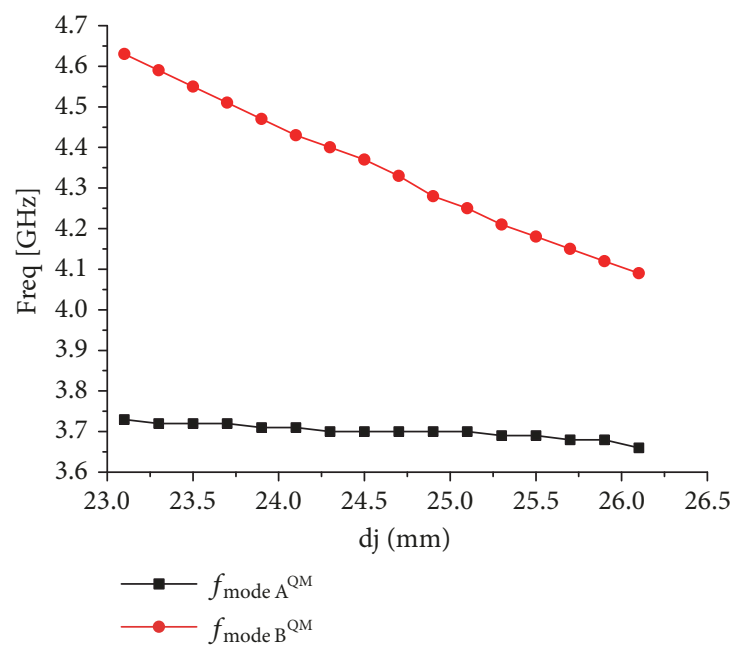

(b)

FIGURE 8: Resonant frequency of QMSIW with different parameters. 


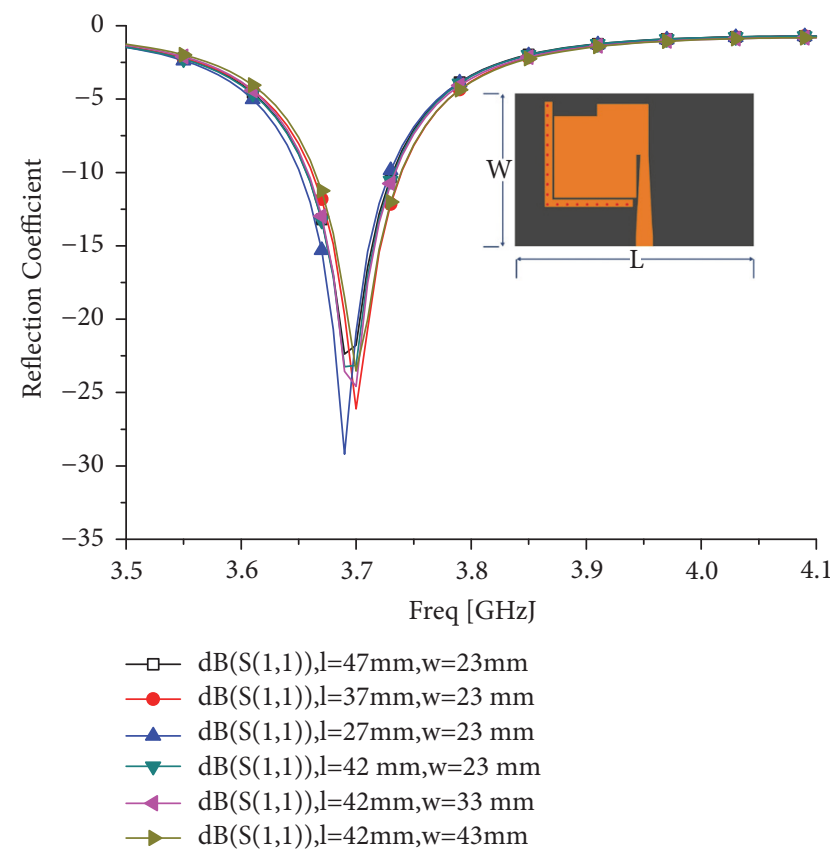

(a)

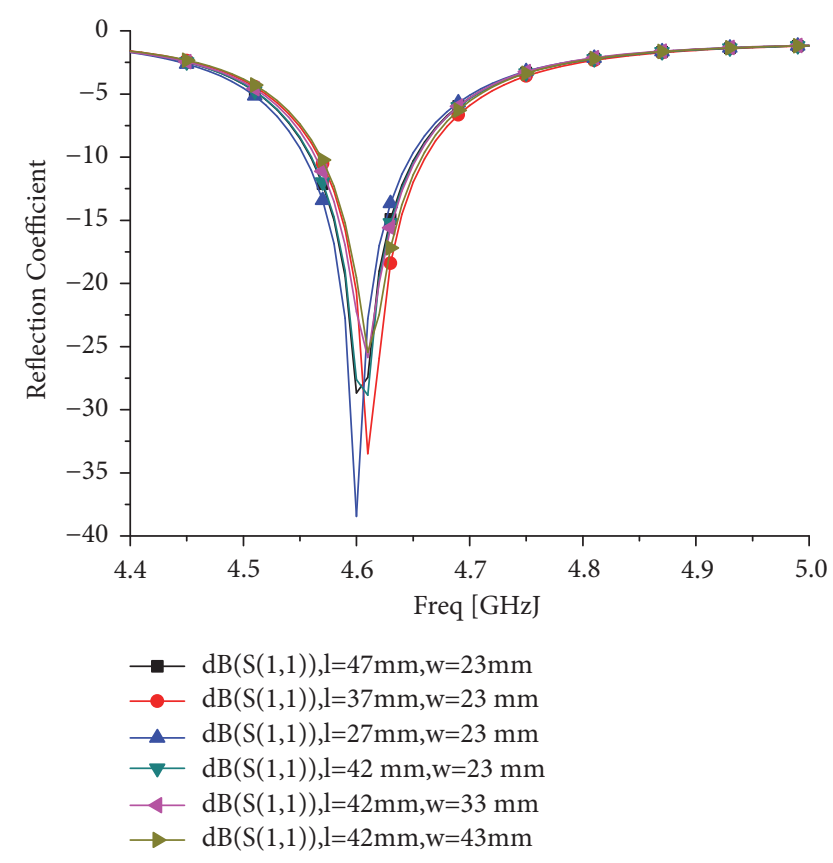

(b)

FIGURE 9: Effect of ground size on antenna reflection coefficient: (a) mode $A^{\mathrm{QM}}$; (b) mode $\mathrm{B}^{\mathrm{QM}}$.

TABLE 1: The effect of the substrate thickness on the antenna performance.

\begin{tabular}{lccc}
\hline Substrate thickness $(\mathrm{mm})$ & Gain & Radiation efficiency $(\%)$ & BW $(\%)$ \\
\hline 0.762 & $3.77 / 4.48$. & $64.7 / 75.2$ & $--/ 1.7$ \\
1 & $3.87 / 3.32$ & $80.7 / 71.3$ & $2 / 2.3$ \\
1.524 & $4.67 / 3.6$ & $87.3 / 83.5$ & $2.7 / 2.6$ \\
\hline
\end{tabular}

TABLE 2: Effect of ground size on radiation performance of antenna.

\begin{tabular}{lccccc}
\hline \multicolumn{2}{c}{$\begin{array}{c}\text { Size of the ground } \\
\mathrm{L}(\mathrm{mm})\end{array}$} & $\mathrm{W}(\mathrm{mm})$ & Gain $(\mathrm{dBi})$ & Mode A & \multicolumn{2}{c}{$\begin{array}{c}\text { Mode B BM } \\
\text { Radiation efficiency }(\%)\end{array}$} & Gain (dBi) & 3.63 & 78.5 \\
\hline 27 & 23. & 4.18 & 85.2 & 4.35 & 84.7 \\
37 & 23 & 4.14 & 84.9 & 4.42 & 84.6 \\
47 & 23 & 4.30 & 84.2 & 4.44 & 84.3 \\
42 & 23 & 4.23 & 84.6 & 4.99 & 83.8 \\
42 & 33 & 4.72 & 84.8 & 5.26 & 83.6 \\
42 & 43 & 4.95 & 84.4 & \\
\hline
\end{tabular}

line width of the port. It means that the possibility of short circuit connection caused by wide line width can be avoided.

\section{Results and Discussion}

The photograph of the proposed antenna is shown in Figure 10. Considering the antenna assembly and measuring, the size of the etched substrate is larger than proposed cavity to facilitate installation. The far field method is used to measure the proposed antenna in the microwave unreflected chamber. Figure 11 shows the measured environment of the antenna which is presented in this paper. The proposed antenna and feed coaxial line are connected by SMA connector.

Figure 12 shows the simulated and measured $\mathrm{S}$ parameter result of the proposed antenna. The input reflection coefficient is measured by N5242a vector network analyser. The resonant cavity size of the antenna is $0.26 \lambda_{0} \times 0.26 \lambda_{0}$. This result indicates that the antenna has been miniaturized. The simulated result is consistent with the measured result.

Figures 13 and 14 show the measured and simulated radiation result of the proposed antenna. Figures 13(a) and 


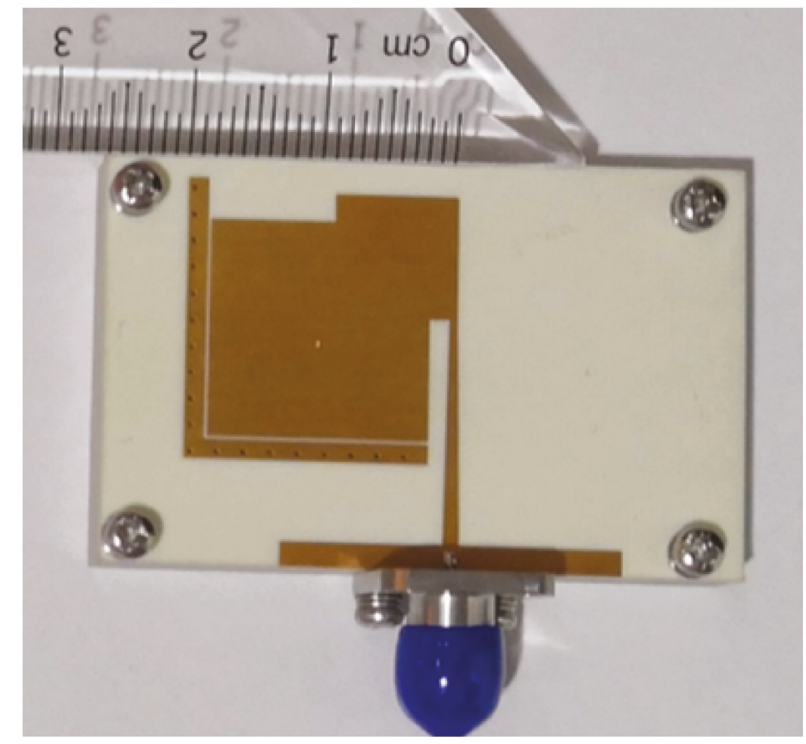

FIGURE 10: Photograph of proposed antenna.

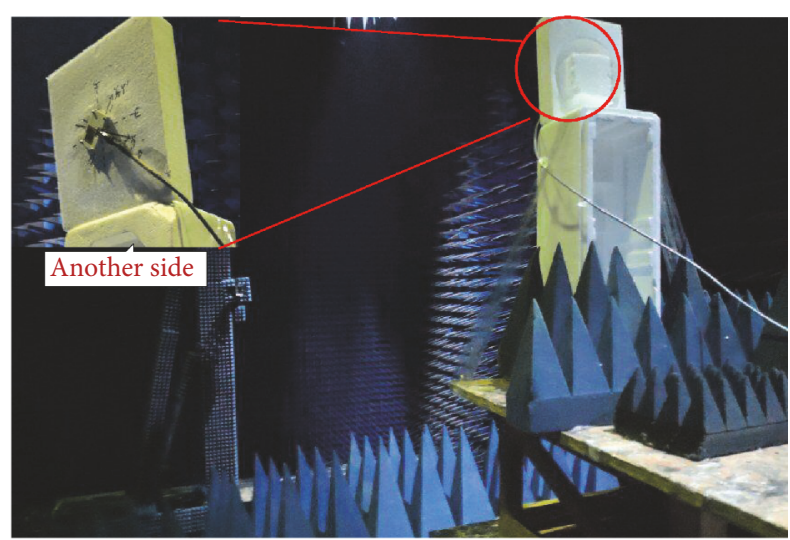

FIGURE 11: Measured environment of proposed antenna.

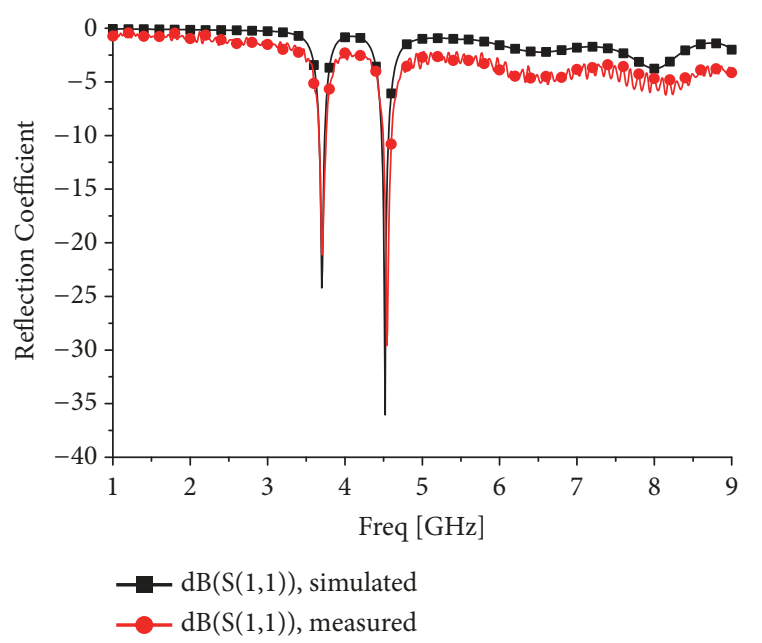

FIGURE 12: Simulated and measured reflection coefficients of the proposed antenna. 13(b) show the $\mathrm{E}$ plane and $\mathrm{H}$ plane pattern in mode $\mathrm{A}^{\mathrm{QM}}$ working at $3.7 \mathrm{GHz}$, respectively. Figures $14(\mathrm{a})$ and 14 (b) show the $\mathrm{E}$ plane and $\mathrm{H}$ plane pattern in mode $\mathrm{B}^{\mathrm{QM}}$ working at $4.6 \mathrm{GHz}$. The electric field is represented by a group of orthogonal distributions in the quarter-mode. When the antenna operates in two modes, the Co-polarizations are orthogonal. The measured results show that the peak gains of the antenna in $3.7 \mathrm{GHz}$ and $4.6 \mathrm{GHz}$ are, respectively, $4.67 \mathrm{dBi}$ and $3.4 \mathrm{dBi}$. The cross-polarization is both less than $-15 \mathrm{~dB}$. It shows that the pattern and the gain are well preserved after being miniaturized. The proposed antenna with dual-frequency orthogonal polarization characteristics can be applied to wireless systems with high channel isolation requirements such as multimode GPS and Satellite Digital Audio Broadcast Systems [11].

Table 3 gives the comparison between the proposed miniaturized cavity-backed antenna and the reported ones. From Table 3, with the decrease of antenna size, the radiation gain of traditional antennas will also deteriorate. However, compared with the reports in Table 3, this work achieves the miniaturization of the back-cavity antenna while achieving good gain and cross-polarization. The radiation characteristics of the proposed antenna are preserved.

\section{Conclusions}

Combining fractal theory and mode segmentation theory, a dual-frequency miniaturized QMSIW cavity-backed antenna with orthogonal linear polarization radiation characteristics based on Minkowski fractal gap is presented in this paper. Firstly, the fractal technique is used to excite a unique fractal mode in the resonator, and the fractal structure increases the electric length of the radiation aperture of the antenna to realize miniaturization. Further, the cavity is cut along 

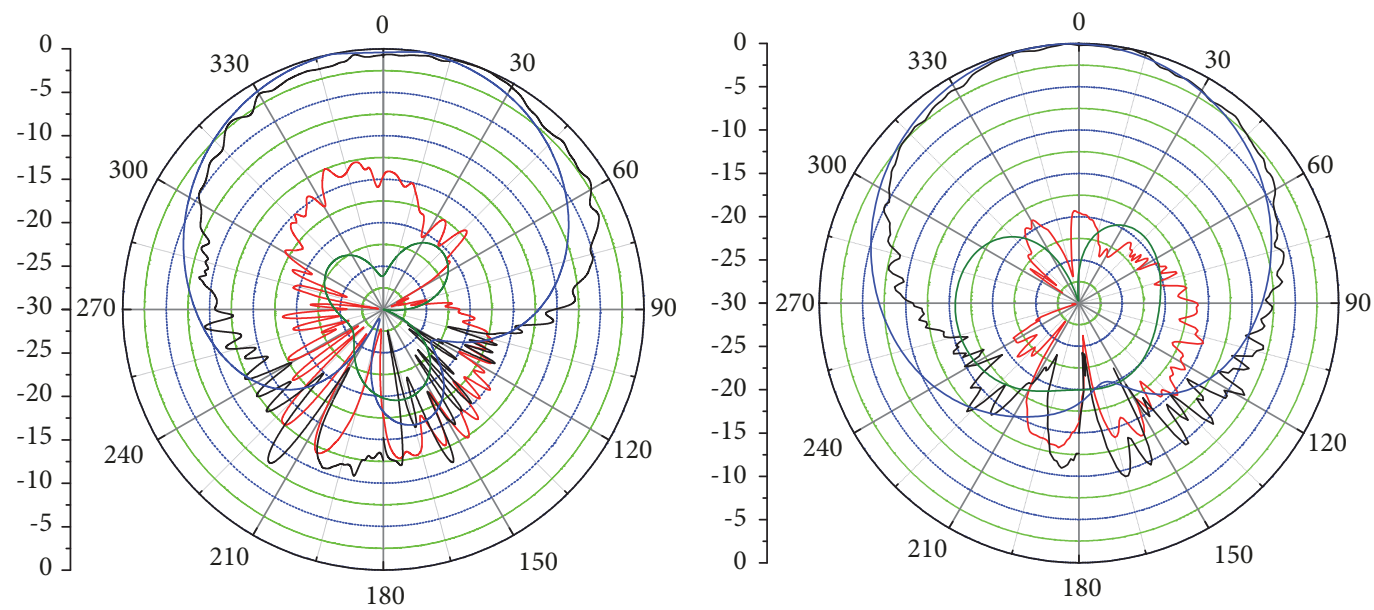

Co-polarization, 3.7GHz,measured
X-polarization, 3.7GHz,measured
$-\quad$ Co-polarization, 3.7GHz,simulated
X-polarization, 3.7GHz,simulated

(a)
- Co-polarization, 3.7GHz,measured
X-polarization, 3.7GHz, measured
$-\quad$ Co-polarization, 3.7GHz, simulated
$\quad$ X-polarization, 3.7GHz, simulated

(b)

FIGURE 13: Measured and simulated radiation patterns of mode A: (a) E plane; (b) H plane.

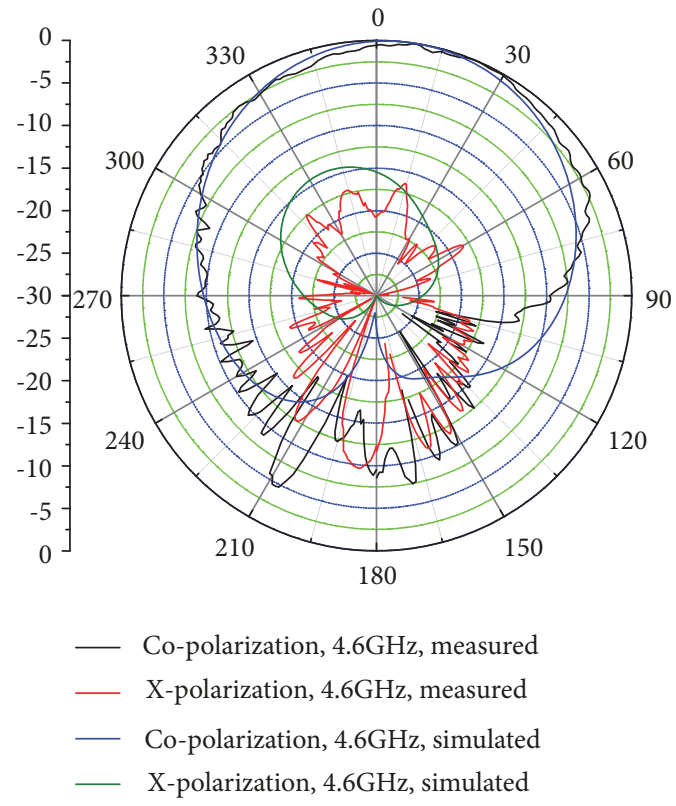

(a)

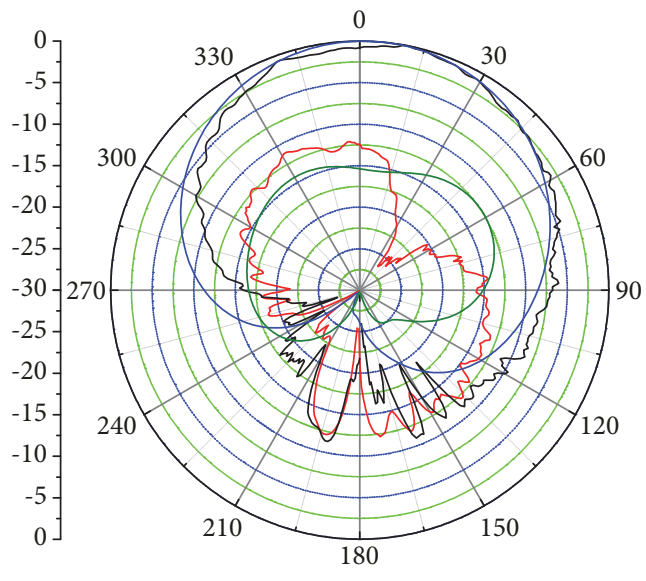

— Co-polarization, $4.6 \mathrm{GHz}$, measured
X-polarization, $4.6 \mathrm{GHz}$, measured
— Co-polarization, $4.6 \mathrm{GHz}$, simulated
X-polarization, $4.6 \mathrm{GHz}$, simulated

(b)

FIGURE 14: Measured and simulated radiation patterns of mode B: (a) E plane; (b) H plane.

the central axis to make the electric field distributed in a quarter-mode. On the one hand, the cavity is further reduced. On the other hand, except for the second and third order modes, the rest of the asymmetric modes below $10 \mathrm{GHz}$ are inhibited. Because the mode splitting path conforms to the electric field distribution law and combines the advantages of high gain of the cavity-backed antenna, the proposed antenna has good radiation characteristics. Besides, the presented antenna presents orthogonal linear polarized radiation in two frequency bands, respectively, because the distribution of electric field is orthogonal. Hence, the proposed antenna has good channel isolation between the two working bands. The cavity size of the proposed antenna is $0.26 \lambda_{0} \times 0.26 \lambda_{0}$. Simulated and measured results show that the radiation characteristics of the antenna are well preserved when miniaturization is achieved. 
TABle 3: Comparison with the reported back-cavity antenna.

\begin{tabular}{|c|c|c|c|c|c|c|}
\hline Ref. & Size $\left(\lambda_{0}\right)$ & Gain $(\mathrm{dBi})$ & Freq $[\mathrm{GHz}]$ & 10dB-BW (\%) & Thickness $(\mathrm{mm})$ & Front-to-back ratio (dB) \\
\hline [9] & $0.34 \times 0.25$ & 4.12 & 5.2 & 3.5 & 1.57 & --- \\
\hline [10] & $0.22 \times 0.16$ & 1.58 & 3.318 & 2.4 & 1.6 & 10 \\
\hline [13] & $0.45 \times 0.15$ & 3.6 & 2.55 & 1.6 & 6.35 & 7 \\
\hline$[14]$ & $0.32 \times 0.48$ & 5 & 2.42 & 2.34 & 3.3 & 15 \\
\hline [15] & $0.4 \times 0.36$ & $4.1 / 5.8$ & $2.4 / 5.8$ & $4.9 / 5.1$ & 3.94 & 10 \\
\hline [16] & $0.6 \times 0.53$ & $3.53 / 5.4$ & $9.98 / 10.6$ & 9.43 & 0.787 & 15 \\
\hline [17] & $1.2 \times 0.9$ & $6.56 / 4.2 / 5.85$ & $4.2 / 5.3 / 5.8$ & -- & 1.57 & 19 \\
\hline [18] & $0.75 \times 0.62$ & $4.8 / 3.74$ & $9.5 / 13.85$ & $2.02 / 1.46$ & 0.787 & $14 / 16$ \\
\hline This work & $0.26 \times 0.26$ & $4.67 / 3.6$ & $3.7 / 4.6$ & $2.7 / 2.6$ & 1.52 & 12.5 \\
\hline
\end{tabular}

\section{Data Availability}

The data used to support the findings of this study are available from the corresponding author upon request.

\section{Conflicts of Interest}

The authors declare that there are no conflicts of interest regarding the publication of this article.

\section{Acknowledgments}

This work was supported by the Natural Science Foundation of China (61471094).

\section{References}

[1] C. P. Baliarda, J. Romeu, and A. Cardama, "The Koch monopole: a small fractal antenna," IEEE Transactions on Antennas and Propagation, vol. 48, no. 11, pp. 1773-1781, 2000.

[2] D. H. Werner, R. L. Haupt, and P. L. Werner, "Fractal antenna engineering: the theory and design of fractal antenna arrays," IEEE Antennas and Propagation Magazine, vol. 41, no. 5, pp. 37$58,1999$.

[3] H. Chen, "Research into the fundamental mode and highorder mode of koch island fractal antenna," Shipboard Electronic Countermeasure, 2014.

[4] Z. U. Islam, M. Rahman, N. Muhammad, Z. Ahmed, F. K. Lodhi, and M. Haneef, "Dual band second order modified Sierpinski monopole reduced size fractal antenna," in Proceedings of the International Conference on Emerging Technologies IEEE, 2017.

[5] W. Yang and J. Zhou, "Wideband low-profile substrate integrated waveguide cavity-backed e-shaped patch antenna," IEEE Antennas and Wireless Propagation Letters, vol. 12, pp. 143-146, 2013.

[6] J. Xu, Z. N. Chen, and X. Qing, "270-GHz LTCC-integrated high gain cavity-backed fresnel zone plate lens antenna," IEEE Transactions on Antennas and Propagation, vol. 61, no. 4, pp. 1679-1687, 2013.

[7] K. Wu, D. Deslandes, and Y. Cassivi, "The substrate integrated circuits - a new concept for high-frequency electronics and optoelectronics," in Proceedings of the International Conference on Telecommunications in Modern Satellite IEEE, 2003.

[8] Y. Cassivi and $\mathrm{K}$. Wu, "Low cost microwave oscillator using substrate integrated waveguide cavity," IEEE Microwave and Wireless Components Letters, vol. 13, no. 2, pp. 48-50, 2003.
[9] C. Jin, R. Li, A. Alphones, and X. Bao, "Quarter-mode substrate integrated waveguide and its application to antennas design," IEEE Transactions on Antennas and Propagation, vol. 61, no. 6, pp. 2921-2928, 2013.

[10] S. Choudhury and A. Mohan, "MiNiaturized quarter-mode substrate integrated waveguide (QMSIW) antenna using Sierpinski fractal geometry," in Proceedings of the Microwave Conference IEEE, 2017.

[11] X. L. Bao and M. J. Ammann, "Monofilar spiral slot antenna for dual-frequency dual-sense circular polarization," IEEE Transactions on Antennas and Propagation, vol. 59, no. 8, pp. 3061-3065, 2011.

[12] X. Bao and M. J. Ammann, "Dual-frequency dual-sense circularly-polarized slot antenna fed by microstrip line," IEEE Transactions on Antennas and Propagation, vol. 56, no. 3, pp. 645-649, 2008.

[13] W. Hong, N. Behdad, and K. Sarabandi, "Size reduction of cavity-backed slot antennas," IEEE Transactions on Antennas and Propagation, vol. 54, no. 5, pp. 1461-1466, 2006.

[14] M. Mujumdar and A. Alphones, "Eighth-mode substrate integrated resonator antenna at $2.4 \mathrm{GHz}$," IEEE Antennas and Wireless Propagation Letters, vol. 15, pp. 853-856, 2016.

[15] S. Agneessens and H. Rogier, "Compact half diamond dualband textile HMSIW on-body antenna," IEEE Transactions on Antennas and Propagation, vol. 62, no. 5, pp. 2374-2381, 2014.

[16] S. Mukherjee, A. Biswas, and K. V. Srivastava, "Broadband substrate integrated waveguide cavity-backed bow-tie slot antenna," IEEE Antennas and Wireless Propagation Letters, vol. 13, pp. 1152-1155, 2014.

[17] D. Chaturvedi, A. Kumar, and S. Raghavan, "An integrated SIW cavity-backed slot antenna-triplexer," IEEE Antennas and Wireless Propagation Letters, 2018.

[18] S. Mukherjee, A. Biswas, and K. V. Srivastava, "Substrate integrated waveguide cavity-backed dumbbell-shaped slot antenna for dual-frequency applications," IEEE Antennas and Wireless Propagation Letters, vol. 14, pp. 1314-1317, 2015. 


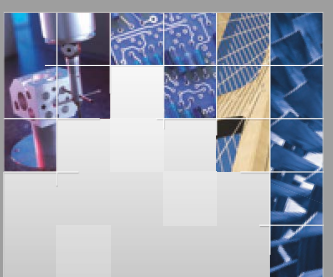

\section{Enfincering}
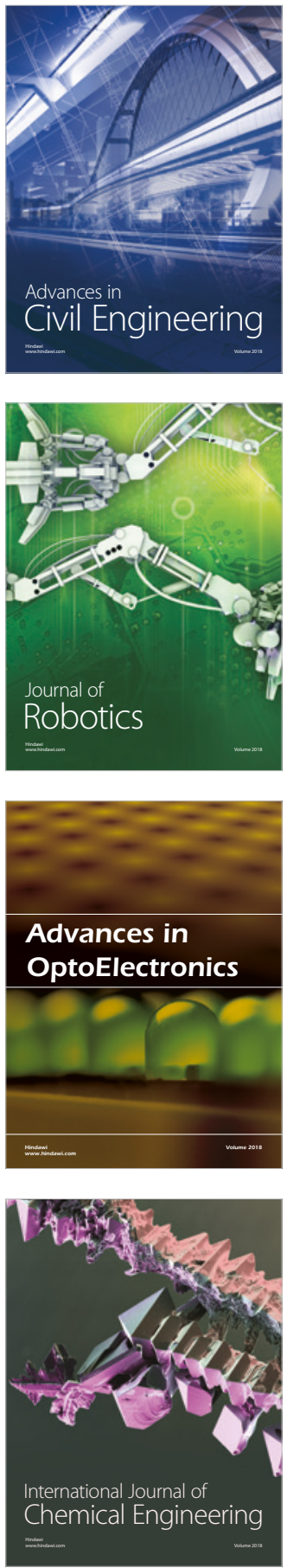

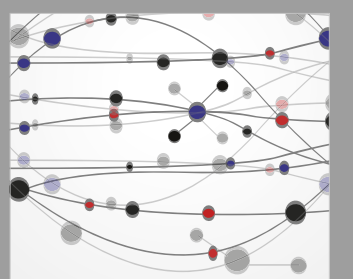

\section{Rotating \\ Machinery}

The Scientific World Journal

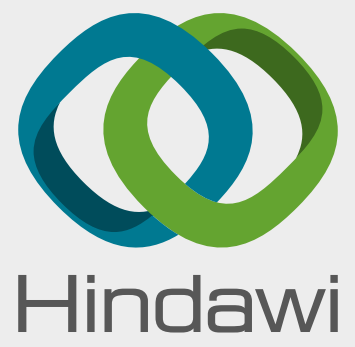

Submit your manuscripts at

www.hindawi.com
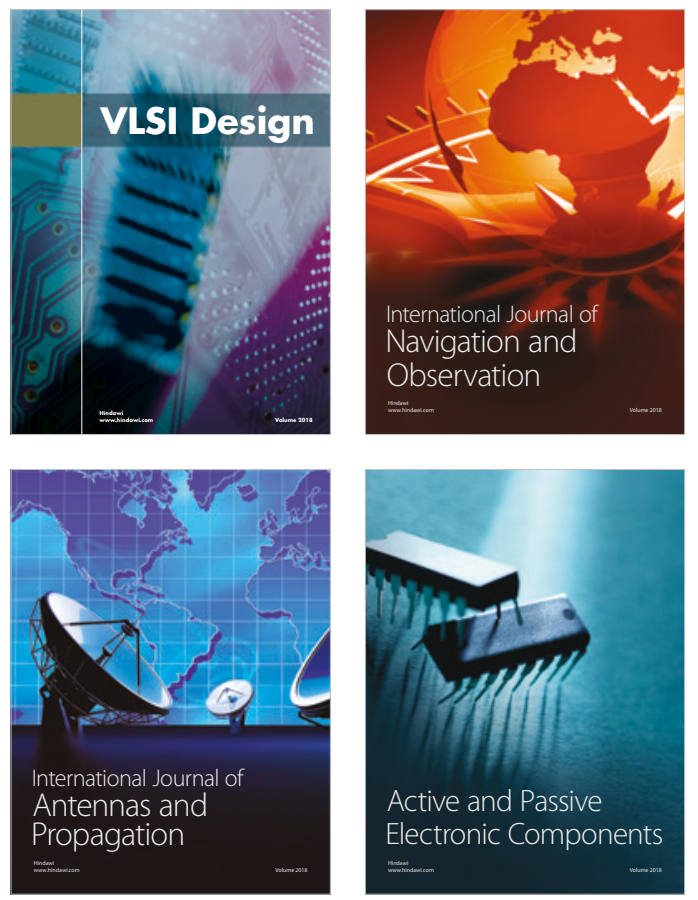
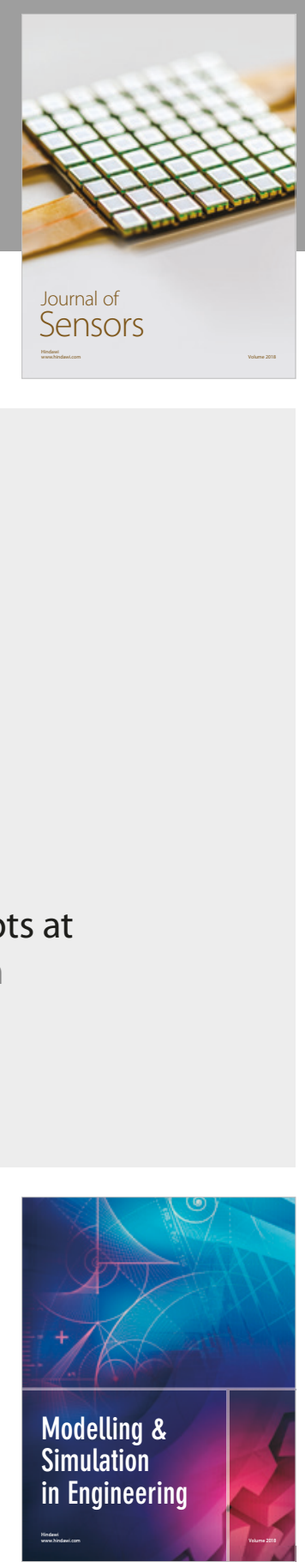

\section{Advances \\ Multimedia}
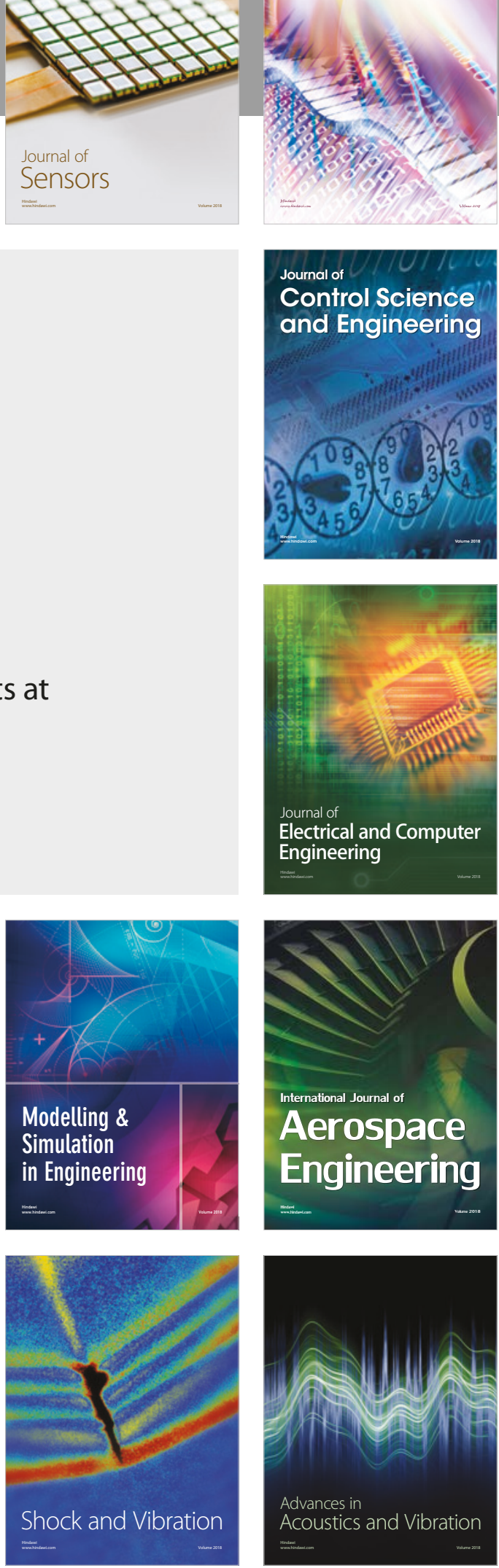